\title{
El derecho a la educación y su desarrollo conceptual desde una perspectiva histórica
}

\author{
Do Direito à Educação e seu desenvolvimento conceitual \\ do ponto de vista histórico \\ The Right to Education and its Conceptual Development \\ from an Historical Point of View
}

\author{
Guillermo Ramón Ruiz \\ Universidad de Buenos Aires (Argentina) \\ Consejo Nacional de Investigaciones Científicas y Técnicas (Argentina) \\ https://orcid.org/0000-0001-8170-2191 \\ gruiz@derecho.uba.ar
}

\section{Resumen}

En este artículo se realiza una conceptualización del derecho a la educación a partir de una perspectiva histórica. En primer lugar, se analiza la historicidad de este derecho, en el marco del desarrollo del liberalismo y del constitucionalismo como procesos convergentes en la configuración de los Estados nacionales modernos. En segundo lugar, se plantean definiciones derivadas del desarrollo del derecho internacional de los derechos humanos y de la propia definición de la educación como un derecho humano fundamental. Finalmente, se presenta un planteo problemático de los alcances de la educación como derecho en función de los procesos históricos recientes de reformas educativas, implementadas por gobiernos de la moderna derecha, las cuales han promovido la privatización educativa.

Palabras clave: Historia del derecho a la educación. Derechos humanos. Privatización de la educación. 


\title{
Resumo
}

Neste artigo é realizada uma conceituação do direito à educação a partir de uma perspectiva histórica. Primeiro, a historicidade desse direito é analisada, no âmbito do desenvolvimento do liberalismo e do constitucionalismo, como processos convergentes na configuração dos Estados nacionais modernos. Segundo, são abordadas as definições derivadas do desenvolvimento do direito internacional dos direitos humanos e da própria definição de educação como um direito humano fundamental. Finalmente, uma problemática do escopo da educação como direito é apresentada com base nos recentes processos históricos de reformas que promovem a privatização educacional.

Palavras-clave: História do direito à educação. Direitos humanos. Privatização da educação.

\begin{abstract}
This article focusses on the conceptualization of the right to education from a historical point of view. First, I analyze the historicity of this right according to the liberalism ideology and the constitutionalism perspective, which are understood as functional processes to the configuration of the modern Nation-States. Second, I define this right following the development of the International Human Rights law, which has included education as one of the core human right. Finally, I explore some of the consequences of the definition of the education as a human right at the recent historical periods, when political reforms were made by right-oriented governments in Western societies and they have promoted the privatization of education.
\end{abstract}

Key words: History of the right to education. Human rights. Privatization of education. 


\section{Encuadre}

Las definiciones contemporáneas del derecho a la educación parecen omitir algunos aspectos sobre todo en lo que atañe a las implicancias formativas que éste posee. Desde el Derecho existe una vasta bibliografía que analiza las concepciones acerca de los derechos sociales en general y su vinculación con las políticas públicas. Sin embargo, aunque la educación está incluida como parte de esos derechos, dicha bibliografía no se focaliza en el análisis de la educación como derecho autónomo sino que lo considera indirectamente a través del estudio de otros derechos conexos como el derecho a la salud, o a la igualdad real de oportunidades, entre otros (Abramovich y Courtis, 2002; Alegre y Gargarella, 2007). Otros trabajos -que provienen de las Ciencias de la Educación- invocan el derecho a la educación pero se limitan al estudio de los problemas y los condicionantes para la realización efectiva de este derecho, o bien hacen hincapié en las condiciones de exclusión, desigualdad e impacto en diferentes sectores sociales (Abritta, 2017; Barrios, 2006; Ezcurra et al, 2019; Finnegan y Pagano, 2008; Más Rocha et al, 2012; Muñoz, 2012). La definición del contenido del derecho a la educación no se establece en estos trabajos; se da por sentado que se entiende qué se quiere decir, o bien se restringe su planteo a las tasas de escolarización y, en el mejor de lo casos, al financiamiento en el sector.

Debe destacarse que en la actualidad, los instrumentos internacionales referidos a los derechos humanos definen diferentes aspectos del derecho a la educación como derecho civil y político, económico, social y cultural, y también como un derecho de niños y jóvenes, y asimismo enfatizan la no-discriminación como el principio de los derechos humanos. Sin embargo, podría resultar significativo conceptualizar el contenido del derecho a la educación en términos de sus implicancias formativas, es decir, de sus alcances en lo que atañe a las definiciones curriculares que constituyen partes sustantivas en términos de oportunidades educativas de los principios de igualdad formal, material y de reconocimiento. Todo lo cual no se restringe a definiciones provistas por las ciencias jurídicas (derecho internacional público, derecho constitucional), sino que requiere de las ciencias de la educación: de la política educacional, de la historia de la educación, de la educación comparada y ciertamente de la pedagogía (Ruiz, 2020).

En este artículo se realiza una conceptualización del derecho a la educación a partir de una perspectiva histórica, en la cual se recuperan las conceptualizaciones históricamente desplegadas desde diferentes encuadres, como forma de contribuir al enriquecimiento de la elucidación de este concepto. En primer lugar, se analiza la historicidad de este derecho, en el marco del desarrollo del liberalismo y del constitucionalismo como procesos convergentes en la configuración de los Estados nacionales modernos, en la era de los derechos. En segundo lugar, se plantean algunas definiciones derivadas del desarrollo del derecho internacional de los derechos humanos y de la propia definición de la educación como un derecho humano fundamental a la luz de los instrumentos internacionales de derechos humanos y de las consagraciones normativas en función del constitucionalismo internacionalizado durante la segunda mitad del siglo XX. Finalmente, se presenta un planteo problemático de los alcances de la educación como derecho en función de las huellas históricas que posee su desarrollo conceptual en el mundo occidental y las posibles cuestiones analíticas que deberían ser problematizadas con atención a las improntas que la historia reciente de las políticas educativas ha dejado en los alcances de este derecho.

\section{Definiciones conceptuales a la luz de improntas históricas de la Modernidad: las libertades, las reformas cristianas y el liberalismo clásico}

Uno de los conceptos centrales de la historia de los sistemas escolares surgidos en el siglo XIX está constituido por la configuración del derecho a la educación. Desde la historia 
de la educación y desde la política educacional el análisis de este derecho permite evaluar los alcances de los fines y objetivos de las políticas educativas ejecutadas desde el Estado así como los procesos históricos de inclusión, progresión y también de exclusión de la población a los saberes socialmente válidos. De forma complementaria -como indicador de la centralidad que tiene la educación como derecho-, es posible mencionar la profunda confianza que poseen las sociedades en la escolarización masiva de la población como forma de contrarrestar las dificultades que presentan otras instituciones gubernamentales y no gubernamentales. Consecuentemente, se suelen incorporar referencias al derecho a la educación en las agendas púbicas, en las plataformas de los partidos políticos de todas las orientaciones ideológicas y en los programas de reformas propuestos por Organismos Internacionales. Allí se suele postular que los problemas sustantivos del presente y la planificación del futuro son cuestiones que podrían ser abordadas y resueltas a partir de la promoción y el desarrollo de la educación. De esta manera, sería fundamental promover el derecho a la educación que sólo resulta invocado y poco definido o, en todo caso, interpretado a su manera por cada promotor o asimilado con la expansión de la cobertura (Ruiz, 2020).

Ahora bien, cabe destacar que el concepto de derecho a la educación surge tardíamente en la historia asociada con el desarrollo de las libertades públicas en el mundo occidental (Volio Jiménez, 1979); y como todos los derechos deben ser analizado a la luz de su propia historicidad. En efecto, según Bobbio (1991), los derechos son temporales, varían en tanto no se trata de entidades inmutables ni ideales a lo largo del tiempo; por el contrario, son redefinidos en función de diversos debates, de las coyunturas históricas y culturales, de las propias correlaciones de fuerzas en cada período, y reflejan el desarrollo de las sociedades. Por ello, es importante reconocer que el estudio de los derechos, como el que aquí nos convoca, debe ser analizado e interpretado en función del contexto histórico y cultural que se demarque. Lo que había prevalecido hasta la Modernidad fue la concepción de los deberes hacia la familia, la autoridad, el grupo de pertenencia, entre otros.

La situación comenzó a cambiar a partir del Medioevo europeo cuando aparecieron reclamos como algunas libertades en torno a la propiedad. De todos modos, fue con la Revolución Francesa de 1789 y luego de la conformación del Estado liberal clásico hacia fines del siglo XVIII que le fueron reconocidos a las personas individuales derechos privados y públicos. Entre los siglos XVI y XVIII, en el marco de la configuración del capitalismo como modo de producción de Europa occidental, los grupos burgueses habían logrado la supresión de trabas materiales y jurídicas para su acción en el contexto de sus enfrentamientos con la organización social medieval. En dicha coyuntura, los individuos gradualmente lograron su autonomía respecto de las comunidades en las cuales se encontraban y comenzaron a afirmar su personalidad y su dignidad esenciales. Por ello, lo que se conceptualiza como derecho era considerado en sus inicios en términos de libertades, de derechos individuales de los que era necesario eliminar las trabas provenientes de la autoridad tradicional medieval, civil o eclesiástica. De esta forma, los principios de libertad individual, de igualdad y seguridad jurídicas, y de propiedad privada, fueron los primeros en ser proclamados e incluidos en los documentos precursores del constitucionalismo (Volio Jiménez, 1979).

En este sentido, Sánchez Viamonte (1907) sostiene que la libertad de enseñanza que durante siglos había dependido del monopolio eclesiástico se convirtió en una conquista social que se encuadraba en aquella lucha por una mayor libertad. Un antecedente importante de esta conquista fue la Reforma Protestante, ya que sus reclamos de acceso a la evangelización en lengua vernácula, junto con la difusión masiva de textos gracias al surgimiento de la imprenta, implicaron la tarea de modificar, en diversas escalas, el plano de las mentalidades de las sociedades por parte de las iglesias protestantes. En efecto, en octubre de 1517 con la publicación de las 95 Tesis de Martín Lutero (1483-1546) se inició una reforma religiosa que cuestionó la jerarquía eclesiástica y postuló la recuperación de las 
prácticas del cristianismo primitivo y el acceso directo a las sagradas escrituras. Junto con la traducción de la Biblia del latín al alemán se propuso a los príncipes la creación de escuelas para que los niños y niñas aprendiesen a leer. En sintonía con este movimiento religioso protestante se agrupaban los intereses de los príncipes y los de algunos sectores de la burguesía que se oponían a la Iglesia, ya que consideraban que su dogma era contrario a los intereses comerciales mercantiles en desarrollo.

El protestantismo pasó de colocar el énfasis en la institución (Iglesia) a enfocarse en el alma como instancia de salvación sin la necesidad de mediadores entre Dios y el individuo. Según Tröhler (2013), este objetivo protestante - de cultivo del alma humana- dio lugar a un nuevo propósito de la educación. Los reformadores protestantes subrayaron la centralidad de la enseñanza. El mismo Lutero (1523) en su obra A los magistrados de todas las ciudades alemanas para que construyan y mantengan escuelas cristianas, sostiene que es fundamental tanto la necesidad de la escuela cuanto la responsabilidad de las autoridades en la enseñanza. La propuesta educativa de los reformadores puede sintetizarse en las siguientes ideas: el planteo del sacerdocio universal y la libertad de conciencia requieren una instrucción universal que implica la creación de escuelas populares; la enseñanza debía ser en lengua vernácula, sobre todo durante la primera infancia, en tanto las lenguas clásicas conservarían su importancia en los circuitos a los que accedían los hijos de los sectores aristocráticos; las escuelas debían estar bajo el control de las autoridades laicas. De esta forma, la Reforma Protestante constituyó un punto de inflexión para la evolución de las libertades de las personas y favoreció la lucha por las libertades civiles en los siglos posteriores. El movimiento reformista protestante se expandió por toda Europa y dio lugar a diferentes confesiones.

A la vez, la Reforma Protestante tuvo su respuesta convergente por medio de la Contrarreforma de la Iglesia Católica y el desarrollo de acciones educativas de mayor alcance como las realizadas por algunas órdenes como los jesuitas. Precisamente, en 1534 Ignacio de Loyola (1491-1556) creó la Compañía de Jesús. El propósito que se perseguía era la conquista y la salvación de las almas de los herejes para evangelizarlos. Los jesuitas promovieron la evangelización no sólo de los adultos sino también de la juventud, dado que ello constituía un instrumento de dominación de las almas. En los años siguientes a la creación de la Compañía de Jesús proliferaron colegios jesuitas que hacia 1586 ascendían a 162, de los cuales 147 aceptaban estudiantes externos. Ello dio lugar a una sistematización de las instituciones (Ratio), cuya versión final estuvo concluida en el año 1599. En dicha sistematización se detallaba la organización académica e institucional de los colegios jesuitas: la enseñanza de las bellas letras, la división de grados, la organización de las lecciones, la creación de sistemas de competencia y emulación, los dispositivos de vigilancia permanente con el fin de formar la mentalidad de los jóvenes para llegar al alma (Durkheim, 1976). Los colegios jesuitas fueron creados por las colonias europeas de ultramar en particular en las de América. Su expansión se detuvo cuando en el marco de las reformas borbónicas iniciadas en la corona española en el siglo XVIII, los jesuitas fueron expulsados de sus dominios.

De esta forma, los reformistas y los contrarreformistas (los jesuitas) dieron lugar a un vínculo más directo entre el niño, concebido como futuro adulto, y su recorrido hacia Dios. Los reformistas consideraban que el cuerpo del niño debía ser educado en una dirección particular (la divina) y ello suponía el reconocimiento de su capacidad racional para ser convencido. La lectura de la Biblia para acceder a la fe o para ser sujeto de una formación específica (la del colegio jesuita), implicaba lograr la conquista del alma y el reconocimiento de un sujeto racional, ya sea como sujeto que puede lograr el autoconvencimiento a través de la guía pastoral protestante, o como sujeto pasible de ser convencido por medio del acompañamiento constante del jesuita. El fortalecimiento del alma en la virtud (posteriormente llamada cívica) es el proyecto pedagógico que se instalaría durante los siglos 
siguientes en una modernidad europea ordenada, que se proponía garantizar el bien común y el progreso (Tröhler, 2013).

Entre los cambios derivados se destaca la organización de lo espacial, sobre todo en el ámbito católico, dado que se produjo una reorganización de los espacios físicos de las iglesias a fin de poder difundir masivamente la doctrina. Se pasó de la iglesia de planta circular destinada a la función del culto simbólico- a la iglesia de planta longitudinal, de grandes dimensiones, en la que era posible reunir gran cantidad de fieles en un ambiente adecuado para la predicación, para la enseñanza de la fe católica. Puede sostenerse que con el advenimiento del cristianismo la enseñanza moral se unió a la religiosa, puesto que se requería la formación de ser que debía salvar su propia alma. Por lo tanto, surgió la necesidad de un ambiente para la predicación y la enseñanza, para la propaganda de la fe, es decir, para la gradual conversión de masas de seres humanos a la fe cristiana. Esto implicaba la necesidad de un ambiente adecuado para la congregación de fieles. Consecuentemente, se integraron y delimitaron, por un lado, el sector destinado a los ministros del culto -en la parte final se mantiene la planta circular- y, por otro, el cuerpo longitudinal para la reunión masiva de fieles, uniéndose las dos funciones: la del rito y la del adoctrinamiento. En algunos de sus documentos oficiales, a raíz de estas transformaciones - la creación de las órdenes religiosas enseñantes y la organización un locus especial para impartir sistemáticamente la doctrina religiosa- la Iglesia Católica Romana se atribuye ser el origen de los actuales sistemas de escolarización masivos (Argan, 1984; Paviglianiti, 1997). ${ }^{1}$

Estas innovaciones en el ámbito de la cristiandad gradualmente se extendieron y convergieron en la conformación de la escuela moderna. De todos modos, de forma contestataria, hacia fines del siglo XVIII, aumentaron las demandas en relación con las libertades de enseñar y de aprender las cuales se integraron a la lucha por la emancipación de las limitaciones sociales vigentes durante siglos: se impondría la libertad de los individuos frente a las iglesias para el ejercicio de lo que hoy se denominan derechos de enseñar y de aprender: "la libertad de enseñanza es traducible por liberación del individuo respecto de la Iglesia para el ejercicio de los derechos de enseñar y aprender" (Sánchez Viamonte, 1907: 20).

Esta concepción diferente y disruptiva tiene un arraigo muy profundo en el plano de las mentalidades y de la política, dado que refleja una modificación en el sustento de la legitimidad del poder: de considerar al soberano -definido por el derecho divino- como eje de la organización social, se pasó a concebir al individuo como núcleo del desarrollo social. Las personas individuales fueron consideradas como poseedoras de derechos que debían ser reconocidos y garantizados por la autoridad estatal. Esta última se limitaría a ejercer las funciones de administrar la justicia, la seguridad del territorio, la seguridad interna, así como a garantizar los derechos individuales. Es conocido en este sentido el planteo de Bobbio cuando sostiene que durante los siglos XVIII y XIX el Estado liberal clásico se conformó a partir de un doble proceso de emancipación que puede ser descripto "como emancipación

\footnotetext{
${ }^{1}$ Sobre esta base organizacional de los espacios de difusión de la doctrina cristiana y de evangelización, diferentes órdenes religiosas desarrollaron espacios de instrucción masiva, con ratios y distribuciones pautadas de docentes y estudiantes que -durante el siglo XIX- fueron la base de la organización de una nueva forma institucional: la escuela moderna sobre la que se organizaron los sistemas educativos modernos. En esta configuración histórica (que aconteció en Europa continental en primer lugar, y posteriormente se expandió a América del Norte y luego a América del Sur, a través de procesos de transferencia internacional de discursos y prácticas) los Estados nacionales modernos también definieron los alcances de la educación escolar como un derecho. Ello puede ser interpretado también como una forma de justificar la obligatoriedad escolar parte de la proclama igualadora que justificaba a esta forma institucional.

La escuela moderna ha sido marcada, entre otros procesos, por la constitución difusa y permeable de sus espacios y las metodologías de enseñanza. A lo largo de su historia incorporó una construcción teórica y estructural que puede ser analizada desde la perspectiva de la forma escolar (Vincent, 1994), así como a partir de los elementos constituyentes de una cultura escolar (Julia, 1995).
} 
entre el poder económico y el poder político" (1985: 147). ${ }^{2}$ A través de dicho proceso el Estado dejó de ser el brazo secular de la Iglesia y pasó a ser el de la burguesía mercantil y empresarial. Por ello, este autor lo definía como un Estado que admitía la pérdida del monopolio del poder ideológico y así explicaba el reconocimiento de los derechos civiles, entre ellos, la libertad religiosa (que suponía el fin del Estado confesional en el mundo occidental); y, a la vez, favorecía la pérdida del monopolio del poder económico ya que concedía la libertad económica.

Al centrarse en particular en los antecedentes y en el desarrollo del proceso revolucionario francés iniciado en 1789, Sánchez Viamonte sostiene que la propia Declaración de los Derechos del Hombre y del Ciudadano muestra el carácter negativo que asume en sus comienzos la liberación de la persona frente a la autoridad absoluta del soberano, cuyo poder se fundaba en el derecho divino. Es por ello que "se fijaron los límites a la autoridad, cuando ella se ejercitaba directamente sobre las personas o sus domicilios [...]. Adquirieron así el carácter de prohibiciones que fueron adoptando formas positivas de derechos individuales, la inviolabilidad de la persona y la inviolabilidad del domicilio, convirtiéndose en el aspecto estático o pasivo de la libertad, que hoy llamamos seguridad individual [...]" (1907: 19-20). Aquellas libertades individuales se correspondían con la liberación de múltiples "trabas jurídicas susceptibles de manifestarse en trabas materiales". Por consiguiente, cada derecho se correspondió con la eliminación de alguna traba autoritaria y "cuando la persona humana es reconocida como tal, positivamente los derechos son inherentes a ella" (Ibid.: 20).

La cuestión educativa no integró el conjunto de derechos vinculados con los principios de libertad negativa y positiva, consagrados durante la conformación del Estado liberal clásico. Sin embargo, es posible pensar que la Revolución Francesa anticipó el debate político educativo de los siglos siguientes ya que una de las primeras medidas tomadas por los revolucionarios fue la secularización de las actividades educativas que estaban en manos de la Iglesia. En la fase jacobina del proceso revolucionario, hacia 1793, se evidenció un avance democratizador de las acciones educativas ya que se proclamó la igualdad básica de los hombres y su acceso gratuito a todas las instituciones educativas que habían sido secularizadas por los revolucionarios. En tal sentido, Paviglianiti (1997) caracteriza el devenir de este derecho a la educación como una construcción histórica polémica dadas las diversas disputas, concepciones y formas de concreción que adoptó en distintos contextos históricos. La autora indaga cómo la educación pasó de ser un monopolio de la Iglesia Católica dentro del mundo occidental cristiano a constituirse como un derecho disputado por distintos sectores y por el Estado. Asimismo, analiza de qué manera la educación pasó de concebirse como un derecho de los individuos a una responsabilidad pública. Según su planteo, el Estado liberal se consolidó durante el siglo XIX como organización política de la sociedad y avanzó en la regulación de las diferentes dimensiones de la vida social, entre ellas, la escolarización masiva. Bajo el pretexto de representar la voluntad general, al Estado le correspondería organizar y dirigir la totalidad del sistema y financiar la educación pública.

Sin embargo, este último supuesto ha sido objeto de discusión en los diferentes contextos nacionales del mundo occidental, en algunos más que en otros, y en casi todos por los conflictos en torno al derecho de los padres para elegir la educación de sus hijos. En el ámbito europeo mediterráneo y en los Estados emergentes de América Latina, la Iglesia Católica Apostólica Romana se presentaba como madre y maestra por considerarse a sí misma como la única mediadora - por derecho divino- entre Dios y los seres humanos. Por el

\footnotetext{
${ }^{2}$ El único monopolio que mantendría sería el uso de la fuerza legítima bajo los límites que imponían los derechos civiles garantizados por los documentos constitucionales que regulaban su uso, y que a la vez configuraban -en términos de Bobbio (1985) - el Estado de Derecho. El Estado liberal se constituyó para asegurar la libre circulación de ideas y la libre circulación de los bienes.
} 
contrario, según el liberalismo clásico, el único agente de la sociedad con capacidad de ejercer la función docente era el Estado ya que representaba el interés colectivo (Durkheim, 1976). Esta alta regulación de la escolarización masiva de la población y su organización sistémica secular por parte de la autoridad estatal ha contribuido a la conformación del Estado Docente. Así se denomina a la unificación y a la organización sistémica de las prácticas escolares preexistentes que fueron absorbidas por las regulaciones estatales en los contextos europeos continentales: nórdicos - primero-, mediterráneos -luego-y americanos en última instancia. Por medio de dichas regulaciones estatales, que se configuraron a través de procesos internacionales de transferencias de prácticas y discursos educativos durante el siglo XIX, se montaron sistemas masivos de instrucción pública, gratuita, organizados en torno a una estructura académica de niveles y modalidades de enseñanza, con un rango de obligatoriedad cada vez más extenso, sobre todo en la segunda mitad del siglo XX.

Sin embargo, en el liberalismo clásico se evidenciaron contradicciones internas en relación con el desarrollo del Estado Docente (como responsable del gobierno de la educación formal) frente al derecho de todos los habitantes de expresar libremente doctrinas e ideas. En consecuencia, no se propondría el monopolio de la educación estatal sino que se admitiría la educación particular a través de su regulación, en términos curriculares y organizativos. Esta regulación del ejercicio del derecho a enseñar por parte de los particulares ha sido cuestionada por la Iglesia Católica durante los últimos dos siglos, ya que disputó esa potestad de regulación y defendió la libertad de enseñanza como principio rector para tener competencias de definiciones curriculares y poder acceder a fondos públicos para el desarrollo de las instituciones educativas privadas. Paviglianiti (1997) sostiene que estas disputas entre el liberalismo clásico y el catolicismo se basan, entre otras motivos, en las diferentes concepciones acerca del principio de legitimidad de las normas que ambas corrientes pregonan. Para los liberales las normas tienen legitimidad siempre y cuando hayan sido dictadas de acuerdo con los procedimientos formales fijados en las Constituciones. Por lo tanto, se reconoce el carácter histórico de acuerdo con los marcos jurídicos e institucionales de los Estados de derecho. Para los católicos, en cambio, la legitimidad es de substancia, es decir que las normas son válidas en tanto sus contenidos se ajusten a los principios teológicos y doctrinarios del dogma cristiano.

\section{Las improntas históricas del siglo XX: el derecho internacional de los derechos humanos, las obligaciones estatales y las críticas de la moderna derecha}

Un punto de demarcación importante desde el punto de vista histórico en lo que atañe a la configuración del derecho a la educación, estuvo dado por la conformación del derecho internacional de los derechos humanos en el contexto de finalización de la Segunda Guerra Mundial. En dicho contexto de posguerra la educación pasó a ser definida como un derecho fundamental de los seres humanos. Los derechos fundamentales consisten en situaciones universales estipuladas directamente como normas generales para todas las personas en su calidad de tales, y que no implican la existencia de por sí de garantías sino que suponen la obligación de introducir dichas garantías (Ferrajoli, 2016). La educación pasó a ser parte de los derechos humanos fundamentales, de contenido prestacional que exigen la intervención positiva del Estado para garantizar su goce a todos los individuos que habitan un país determinado. Ello aconteció a partir de la conformación de la Organización de las Naciones Unidas (ONU) en 1945 y, sobre todo, cuando en 1948 se aprobó la Declaración Universal de los Derechos Humanos. El afianzamiento del derecho internacional sobre derechos humanos, y la consiguiente irrupción de los instrumentos internacionales de derechos humanos y su incorporación a los textos constitucionales han posibilitado que nuevos procesos y fenómenos jurídicos ampliasen el debate sobre la naturaleza y los alcances del derecho a la educación y los correlativos niveles de obligaciones a cargo del Estado. 
En el ámbito europeo, la mayoría de los países occidentales aprobaron Constituciones que reflejaron los cambios económicos y sociales ocurridos en los años previos, así como las reacciones a las formas fascistas de organización de los Estados de las décadas precedentes. En dichos textos constitucionales europeos, se adoptó a la democracia representativa liberal para fundamentar la organización institucional del Estado (ya se tratase de Estados republicanos o de monarquías constitucionales), y se reconocieron nuevos derechos políticos y sociales al conjunto de la población. Asimismo, se incorporaron en las Constituciones las novedosas formas de regulación política que daban cuenta de los cambios en los procesos de diseño y ejecución de políticas públicas así como de negociación neocorporativista, a través de la institucionalización de consejos con representación tripartita que daban cuenta del desarrollo de las instituciones del Estado Keynesiano de Bienestar o Estado social (Isuani, 1991).

Según Ferrajoli (2016), en los países europeos como Italia, Alemania, España y Portugal que atravesaron la experiencia del fascismo, se aprobaron constituciones rígidas en el plano jurídico, es decir, caracterizadas por mayor fuerza normativa y garantista. Dicho constitucionalismo rígido permitió constitucionalizar no sólo los derechos de libertad, los derechos civiles, sino además los derechos sociales como derechos fundamentales. ${ }^{3}$ Todo ello daba cuenta de una transformación en la forma del Estado, que pasaba de ser básicamente protector-represor a ser cada vez más promocional: el Estado no sólo debía impedir sino que debía promover; no resultaba suficiente la visión de la justicia conmutativa -basada en el criterio de la igualdad formal-, sino que debía promoverse la justicia distributiva, es decir, distribuir pero con arreglo a algún criterio. La gran transformación del siglo XIX exigió que el Estado asumiera responsabilidades frente a la urbanización, la industrialización y la proletarización de la sociedad (Polanyi, 1989). En tal sentido, la institucionalización de la educación escolar a través de sistemas masivos de escala nacional constituyó una de esas respuestas, que alcanzó una escala global luego de la Segunda Posguerra.

De acuerdo con Ferrajoli (2016), los derechos sociales han nacido precisamente para resolver problemas educativos, sanitarios y de vivienda que en las sociedades tradicionales estaban bajo la órbita de las iglesias o que no existían o no se resolvían. Más aun, a partir del siglo XX el hecho de sobrevivir es artificial y social ya que depende del grado de integración social de las personas: la división social del trabajo y la urbanización cada vez mayor de las sociedades dio lugar a personas cada vez menos autosuficientes, por lo que su vida depende cada vez más de una esfera pública con mayores niveles de complejidad en términos burocráticos y de financiamiento. Los derechos sociales refieren así a atributos y medios para vivir de forma libre y digna.

Como se notó previamente, en aquel contexto de posguerra, la Declaración Universal de los Derechos Humanos constituyó el instrumento que dio origen a un sistema universal de protección de estos derechos bajo el compromiso político de los Estados de asumir un conjunto de obligaciones para respetarlos, garantizarlos, favorecerlos y promoverlos. El artículo 26 de esa Declaración refiere a la educación y sienta las bases de su definición como derecho humano al establecer que toda persona tiene derecho a la educación y especifica que ésta debe ser gratuita en lo que refiere a la instrucción elemental y básica. Según este artículo, al tratarse de un derecho, la educación debe tener como propósito el pleno desarrollo de la personalidad humana y el

\footnotetext{
${ }^{3}$ Para este autor, el garantismo es un rasgo específico del constitucionalismo europeo del siglo XX. En su esquema analítico las garantías son prohibiciones y obligaciones presentes en los derechos constitucionalmente establecidos: los derechos de libertad suponen un paso atrás para el Estado, dado que existen prohibiciones para intervenir en la esfera de las libertades que garantizan la autodeterminación individual; por su parte, los derechos sociales implican un paso adelante, en tanto obligan al Estado a intervenir en la vida de los ciudadanos para garantizar las correspondientes prestaciones sociales. Las garantías constituyen tanto las prohibiciones como las obligaciones correlativas a los derechos fundamentales en el paradigma de la democracia constitucional a partir del siglo XX, debido a que conforman un bloque de límites y de vínculos impuestos a todos los poderes, tanto públicos como privados, políticos o económicos (Ferrajoli, 2016).
} 
fortalecimiento de los derechos humanos sobre la base del respeto y de las libertadas humanas. Los Estados desde entonces han ratificado el reconocimiento de la educación como derecho humano, y ella ha sido incorporada en los cinco instrumentos internacionales más significativos de derechos humanos que -ordenados cronológicamente- son los siguientes:

- La Convención sobre la eliminación de todas las formas de discriminación racial (aprobado en 1965, entró en vigencia en 1969; 169 Estados lo han suscripto)

- El Pacto Internacional de Derechos Civiles y Políticos (aprobado en 1966, entró en vigencia en 1976 y cuenta con la suscripción de 151 Estados)

- El Pacto Internacional de Derechos Económicos, Sociales y Culturales (aprobado en 1966, entró en vigencia en 1976 y cuenta con la suscripción de 148 Estados)

- La Convención sobre la eliminación de todas las formas de discriminación contra la mujer (aprobado en 1979, entró en vigencia en 1981 y cuenta con la suscripción de 174 Estados)

- La Convención sobre los derechos del niño (aprobado en 1989, vigente desde 1990, con la suscripción de 174 Estados)

A ellos se debe sumar para el ámbito continental americano la Convención Americana de Derechos Humanos conocida como el Pacto de San José de Costa Rica (aprobado en 1969, entró en vigencia en 1978 y cuenta con la adhesión de 25 Estados de la región). En el contexto europeo, pueden distinguirse las normas aprobadas en el marco del Consejo de Europa (Convenio Europeo de Derechos Humanos y su protocolo primero, y la Carta Social Europea) y aquellas que refieren al ordenamiento de la Unión Europea, en particular la Carta de Derechos Fundamentales de la Unión Europea (Meix Cereceda, 2014). Por otra parte, los dos Pactos aprobados en 1966 sobre derechos civiles y políticos y sobre derechos económicos, sociales y culturales, han tenido un alto impacto en la definición de la educación como derecho humano fundamental, dado que partieron de la necesidad de traducir y operacionalizar los principios establecidos en la Declaración Universal de 1948. Para ello, han definido obligaciones concretas y específicas a cargo de los Estados en materia educativa. Es importante destacar además que la aprobación de estos instrumentos internacionales de derechos humanos dio lugar a la conformación de organismos internacionales de interpretación de estos instrumentos así como de monitoreo y control de las acciones de los Estados. En el marco del sistema internacional de derechos humanos, se encuentran el Comité de Derechos Humanos y el Comité de Derechos Económicos, Sociales y Culturales; y en el contexto regional americano estas tareas de interpretación y monitoreo están a cargo de la Comisión Interamericana y de la Corte Interamericana de Derechos Humanos.

En este sentido resulta ejemplar la jurisprudencia y la doctrina de los organismos internacionales, entre cuyos trabajos se destacan la observación del Comité de Derechos Económicos, Sociales y Culturales en relación con el artículo 13 de dicho Pacto de Derechos Económicos, Sociales y Culturales, ${ }^{4}$ así como los trabajos realizados por la primera Relatora Especial para el derecho a la educación de la Comisión de Derechos Humanos de la ONU: Katarina Tomasevski. De hecho, el artículo 13 del Pacto Internacional de Derechos Económicos, Sociales y Culturales ha sido objeto de una exégesis tanto por parte del Comité de Derechos Económicos, Sociales y Culturales (en su Observación General $N^{\circ} 13$ ) como del desarrollo analítico realizado por Tomasevski en su rol de Relatora Especial de Naciones Unidas sobre el derecho a la educación. Ambos estudios - la OG $\mathrm{N}^{0} 13$ y el catálogo de

\footnotetext{
${ }^{4}$ Existen importantes definiciones formuladas por los demás instrumentos internacionales de derechos humanos en materia de derecho a la educación, entre los cuales sobresalen (por la cantidad de Estados que los han suscripto, su antigüedad y el impacto que han tenido): el Pacto Internacional de Derechos Civiles y Políticos (artículo 18), la Convención sobre la eliminación de todas las formas de discriminación racial (artículos $5^{\circ}$ y $7^{\circ}$ ), la Convención sobre la eliminación de todas las formas de discriminación contra la mujer (artículo 10) y la Convención sobre los derechos del niño (artículo 28), entre otros.
} 
contenidos de este derecho efectuado por Tomasevski- constituyen una caracterización exhaustiva del contenido del derecho a la educación a partir de las obligaciones internacionales en materia educativa que, aunque no agotan la tarea, pueden traducirse en un catálogo de contenidos básicos de este derecho.

Tal como afirma Tomasevski $(2004 ; 2001)$, el derecho a la educación hace referencia no sólo a un derecho de los individuos a recibir educación sino, como todo derecho humano, también implica obligaciones estatales específicas. Los contenidos centrales del derecho a la educación a partir de este catálogo de posiciones jurídicas garantizadas que se desprenden de las obligaciones de los Estados en materia educativa, pueden estructurarse en torno al esquema de las cuatro $A$ : asequibilidad, accesibilidad, aceptabilidad y adaptabilidad (Tomasevski, 2001). Como se ha mencionado anteriormente, el derecho a la educación comprende desde el plexo normativo internacional un importante catálogo de obligaciones a cargo de los Estados nacionales. De acuerdo con un criterio de clasificación que tome en cuenta su contenido, estas obligaciones pueden clasificarse como (Ruiz y Scioscioli, 2017):

1) Obligación de respetar. Esta obligación se observa cuando el derecho a la educación se comporta como derecho de prestación negativa o no-intervención, en el sentido de prohibir la obstaculización en el ejercicio del derecho que alguien ya puede realizar por sus propios medios o por los medios generados por el Estado u otros actores sociales. La obligación de respetar implica que el Estado se abstenga de injerir directa o indirectamente en el disfrute del derecho social.

2) Obligación de proteger. Esta obligación exige a los Estados adoptar leyes u otras medidas que resulten necesarias para evitar o prevenir que los particulares $\longrightarrow$ sea, otros sujetos diferentes al Estadoproduzcan dichos perjuicios. La obligación de protección reviste en el derecho a la educación un derecho subjetivo que no se limita a meros deberes del tipo objetivo en cabeza del Estado como un simple prestador de un servicio público. Implica además la obligación de que el Estado organice el sistema educativo de acuerdo con algún tipo de medidas para evitar que otros individuos u actores obstaculicen, o interfieran de algún modo en el ejercicio del derecho a la educación y de sus posiciones garantizadas a sus sujetos activos. En este ámbito se incluyen las medidas que el Estado debe adoptar cuando, por ejemplo, en la educación privada se evidencia alguna disposición que obstaculice indebidamente (por medio del ejercicio abusivo de su libertad de contratación o el derecho de admisión) el acceso o permanencia de un docente o de estudiante en un establecimiento educativo privado.

3) Obligación de cumplir, realizar y garantizar. Este aglomerado de obligaciones es quizás el más interesante en función del contenido social del derecho a la educación y de cara al contexto de exclusión social que afecta a la región latinoamericana en general, y en particular respecto del colectivo de niños y niñas. La obligación de cumplir se define como la necesidad de que los Estados reconozcan suficientemente el derecho a la educación en sus sistemas políticos y en sus ordenamientos jurídicos nacionales, y que adopten una política nacional acompañada de un plan detallado para el ejercicio del derecho. Cabe aclarar que en la obligación de cumplir no sólo se incluyen las obligaciones de prestación - acción positiva de otorgar cosas concretas como subsidios y recursos escolares-, sino también aquellas de desarrollo normativo que contemplan el dictado de reglas y procedimientos que permitan organizar un sistema administrativo y de justicia eficaz y de acceso igualitario. Por ello, no es suficiente con que una ley de educación se llene de términos sobre la educación como derecho para todas las personas; es preciso, además, que se generen y se ejecuten planes y programas con financiamiento específico y suficiente para implementarlos.

Podría sostenerse que el planteo histórico iniciado en aquel contexto de la Segunda Posguerra Mundial se mantiene vigente en términos discursivos pero también a través de las divergentes respuestas que se dan en torno al criterio a adoptar para la distribución social. "Los derechos sociales cuestan pero el Estado no es una sociedad con ánimo de lucro. Su razón social reside en la garantía de los derechos estipulados en su Constitución, exactamente 
como el fin de lucro define la razón social de una sociedad comercial" (Ferrajoli, 2016: 65). Sin embargo, desde fines de la década de 1970 este planteo histórico surgido luego de la Declaración de 1948 ha sido objeto de críticas a partir de los procesos de recomposición de la derecha moderna, ya que sus propuestas han criticado las instituciones del Estado Keynesiano de Bienestar y los derechos sociales por su alto costo al erario público. Estas posturas han comenzado a propugnar nuevas formas de regulación y financiamiento como la de la educación pública, que ha sido redefinida y no necesariamente en términos de derecho.

A partir de los procesos de reforma del Estado es posible identificar en el debate contemporáneo, propugnado desde diferentes ámbitos internacionales, tanto políticos como académicos, divergentes opiniones sobre la educación escolar, y sobre las orientaciones que deben seguirse en los Estados para el desarrollo de los sistemas educativos contemporáneos. En dichos debates, suelen omitirse las definiciones sobre la educación como un derecho humano y se la presenta como un bien público o incluso como un bien de mercado aunque esta acepción es poco aceptada (Ruiz, 2020). Por una parte, cuando se define a la educación como bien público se hace referencia a un concepto que no posee una definición unívoca. Podría adoptarse la acepción que lo define como un bien que genera beneficios o utilidades apropiables conjuntamente por la comunidad en forma grupal. Aunque el beneficio no es para todos igual, sí lo es el hecho de que nadie queda excluido de su consumo o uso: el consumo está garantizado para todas las personas. Desde la perspectiva de algunos organismos internacionales de financiamiento, la educación básica integra el listado de bienes públicos. ${ }^{5}$ Ello ha cuestionado directamente el rol del Estado en la educación, lo cual demuestra la marcada diferencia entre el liberalismo clásico y el neoliberalismo ${ }^{6}$ en este terreno, y afecta la propia conceptualización de la educación como derecho. Las propuestas neoliberales de reconversión de la educación deben ser encuadradas en su cuestionamiento al costo que según ellas suponen los derechos sociales, que al tornarse en una carga que debe ser costeada con impuestos, constituyen un factor de desinversión por parte del capital. Ello redundaría en un ciclo de recesión, pérdida de empleo y empobrecimiento generalizado que sólo puede ser revertido a través de la desregulación del mercado económico.

Consecuentemente, en muchas de esas políticas de reformas del Estado -a partir de las últimas décadas del siglo pasado- la educación escolar ha sido objeto de un conjunto de medidas que favorecieron su redefinición no como derecho sino como un bien de mercado, o como un bien público. En diferentes países, la desregulación de la educación privada fue instrumentada como respuesta a la ineficacia y a la ineficiencia de lo público denunciadas por los discursos favorables a las reformas. Por consiguiente, diferentes gobiernos han arremetido contra la educación pública e instrumentado políticas que implicaron cambios notorios en las finalidades de la escuela púbica y en sus prácticas, y con ello han cercenado el ejercicio del derecho a la educación (Frigerio, 2000; Kaufman y Nelson, 2005; Vior et al., 2016). Las consecuencias generadas por estas políticas de mercantilización de la educación distan de ser las prometidas por sus propulsores (Ball, 2014; Heinrich y Nisar, 2013; Santa Cruz Grao y Olmedo, 2012). Diferentes estudios -en distintos países- han demostrado que la exacerbación de la competencia entre las instituciones escolares en los cuasi-mercados educativos locales, en lugar de aumentar la diversidad, dieron pie

\footnotetext{
${ }^{5}$ Por otra parte, pensar a la educación como bien de mercado implica definirla como una mercancía. Todos los bienes de mercado se caracterizan porque generan beneficios o utilidades que pueden ser apropiadas única y exclusivamente por el individuo que los consume; son bienes que se ajustan al principio de exclusión, es decir, resulta posible excluir del consumo a quien no haya relevado sus preferencias en el mercado, por no ofrecer pagar un precio por ello: si alguien no paga, queda excluido del consumo de la mercancía. En algunos casos de propuestas de reforma de la derecha moderna, como las británicas instrumentadas a partir de la década de 1980, se perciben estas orientaciones en la definición de la educación escolar y de un cuasi mercado educativo (Whitty et al. 1999).

${ }^{6}$ Sin embargo, si bien es cierto que el financiamiento de los derechos sociales es costoso, su cercenamiento o inexistencia sería más costoso aún. Países como los ubicados en África subsahariana no cuentan con derechos sociales. Allí la inexistencia de políticas sanitarias, alimentarias y educativas da lugar no sólo a epidemias y desnutrición, sino además a la muerte de millones de personas, y precisamente estas condiciones deplorables de vida de las personas no constituyen ningún incentivo para la productividad o el desarrollo económico (Ferrajoli, 2016).
} 
a la instrumentación de modelos de gestión mercantilista para atraer a los estudiantes y a los docentes considerados más meritorios en función de las evaluaciones cada vez más periódicas de las instituciones y de sus actores, a la par que aumentaron los procesos de exlusión (Lawn, 2013; Olmedo, Bailey, Ball, 2013; Verger et al., 2016).

Por otra parte, como parte de las contradicciones políticas e ideológicas que ha despertado históricamente la educación como derecho, durante la década de 1980 en el marco de la ejecución de políticas de ajuste estructural y austeridad en los gastos que suponían la implementación de políticas sociales, se llevó a cabo un intenso debate sobre los roles y las responsabilidades que tienen los Organismos Internacionales surgidos a mitad del siglo XX. Es así que en la década de 1980 se evidenció la presencia cada vez más notoria (como fuente de recursos financieros internacionales destinados a programas educativos) de Organismos Internacionales de financiamiento. En particular el Banco Mundial se convirtió en la fuente más importante de recursos financieros destinados al desarrollo educativo y en la usina de políticas de reformas educativas particularmente incisivas y penetrantes en los países con economías más pobres y con bajos niveles de desarrollo humano. Altamente influido por las orientaciones ideológicas del gobierno de los Estados Unidos, el Banco Mundial dio lugar al desarrollo de un marco político de reformas educativas que promovían la reconfiguración de los sistemas escolares (sobre todo de los países más pobres, receptores de los préstamos internacionales de esta entidad bancaria), para acotar sus costos, reducir su burocracia y promover la inversión estratégica de los préstamos monetarios en capital humano a efectos de lograr el crecimiento económico de los países más pobres. El uso de mecanismos e instrumentos competitivos de mercado se comenzó a introducir en los sistemas escolares, con mayores o menores niveles de adaptación (por parte de las autoridades estatales) y de resistencias sociales por parte de las comunidades educativas de cada país (Ruiz, 2016).

\section{Discusiones y conclusiones: la historia contemporánea del derecho a la educación ante el avance de las tendencias a la privatización}

La historia problemática de la configuración conceptual y política del derecho a la educación ha tenido diferentes improntas en los contextos europeos y americanos. La conformación de las libertades a finales del Medioevo junto con los conflictivos movimientos de reformas religiosas y la consolidación del capitalismo como modo de producción a la par que abrieron demandas por libertades de enseñanza, y favorecieron procesos de escolarización masiva de la población infantil, dieron lugar a formas institucionales de escolarización masivas y funcionales a la sociedad moderna que se configuraba. Si durante el siglo XIX la escuela moderna apareció como un aparato ideológico del Estado (Althusser, 1988), en el siglo pasado -en cambio- las improntas de la Posguerra y la conformación del derecho internacional de los derechos humanos y del Estado Keynesiano de Bienestar han sido claves para definir a la educación como un derecho humano fundamental. Ello generó un plexo normativo vigoroso que conllevó el establecimiento de obligaciones estatales que deben ser el resguardo para que la población pueda ejercer y gozar de este derecho a la educación que supone (desde el punto de vista conceptual y también político) fortalecer el desarrollo humano como un proceso de concientización a través del acceso al conocimiento. Cabría debatir no obstante los alcances de dicho proceso, sobre todo en contextos como los contemporáneos que a pesar de las improntas históricas y de las obligaciones estatales definidas contradicen -desde las políticas públicasalgunas de las definiciones que la historia del derecho a la educación ha consagrado.

En las últimas dos décadas del siglo XX a la par que se daba el debate dentro de las organizaciones de las Naciones Unidas sobre su rol y responsabilidad internacional en la promoción de la educación básica para todos y todas, el Banco Mundial, por su parte, se convirtió (entre otros Organismos Internacionales de financiamiento) en el mayor agente internacional promotor de reformas educativas a escala global y tuvo un rol decisivo en el diseño de los 
procesos de reforma estructural de los Estados, los que hacían frente a su vez a la crisis de la deuda. De esta forma, los procesos de reforma de la educación pública auspiciados por este Organismo Internacional, en todo el mundo incluyeron la desregulación de la educación privada, la incorporación de mecanismos de competencia entre usuarios e instituciones para el acceso al servicio educativo, la introducción de aranceles y tasas por la prestación de la educación en algunos de sus niveles y la adopción de criterios de eficiencia empresarial para evaluar los resultados de los sistemas educativos (Ruiz, 2016).

Es aquí donde se ubica el paradigma de políticas públicas, denominado en inglés responsiveness, que supone mejorar la capacidad de respuesta de los servicios públicos. Se supone que es posible lograr una mejor capacidad de respuesta de los sistemas y servicios sociales a las demandas de la comunidad inmediata. Para ello se requiere una redistribución de las responsabilidades en el proceso de toma de decisiones, por lo cual los usuarios de los servicios deben poder participar e incidir directamente en dicho proceso. En el caso de la educación, se ha evidenciado la promoción global de reformas escolares que incluyeron políticas de descentralización educativas que estaban a la vez incluidas en los procesos de reforma estructural de los Estados. Estas políticas apuntaban a lograr una reducción del Estado nacional y una paralela expansión de la injerencia de los Estados jurisdiccionales y locales, así como del sector privado. En este sentido, algunos autores diferencian entre la privatización en y de la educación (línea de análisis que diferencia entre las denominadas dinámicas endógenas y exógenas de la privatización). La primera refiere a la privatización encubierta en la educación, es decir, a "la importación de ideas, métodos y prácticas del sector privado a fin de hacer que el sector público sea cada vez más como una empresa y crecientemente comercial" (Ball y Youdell, 2008: 8). La segunda implica "la apertura de los servicios de la educación a la participación del sector privado, a través de modalidades basadas en el beneficio económico, así como la utilización del sector privado en cuanto a la concepción, la gestión o la provisión de diferentes aspectos de la educación pública" (op.cit.: 9). Se piensa así en usuarios de servicios y no en sujetos titulares de un derecho humano fundamental.

En suma, tal como lo ha planteado Paviglianiti (1997) la construcción histórica del derecho a la educación ha sido problemática durante la era de los derechos (Bobbio, 1991), y si bien las definiciones normativas derivadas del derecho internacional de los derecho humanos han establecido indicadores claros para definir el contenido de este derecho, al menos desde el punto de vista de las obligaciones de los Estados, las redefiniciones de la educación tanto como bien público o como bien de mercado cercenan el alcance de aquellas obligaciones estatales. Es más, en algunos casos hasta las omiten o desconocen. En diferentes Estados, o incluso en algunas regiones dentro de los países, las políticas educativas contemporáneas promueven procesos que desmantelan el derecho a la educación y desconocen su historia y sus implicancias en materia de desarrollo humano.

\section{Referencias}

Abramovich, V. y Courtis, C. (2002). Los derechos sociales como derechos exigibles. Madrid: Trotta.

Abritta, A. (2017). Creación de alternativas pedagógicas para el ejercicio del derecho a la educación en jóvenes y adultos: el caso del Plan Fines en la Provincia de Buenos Aires (Argentina). Revista Latinoamericana de Educación Inclusiva, 11 (2), 21-33 https://doi.org/10.4067/S0718-73782017000200003

Althusser, L. (1988). Ideología y aparatos ideológicos del Estado. Freud y Lacan. Buenos Aires: Nueva Visión.

Argan, G. (1984). El concepto del espacio arquitectónico desde el Barroco a nuestros días. Buenos Aires: Nueva Versión. 
Ball, S. (2014). Globalización, mercantilización y privatización: tendencias internacionales en Educación y Política Educativa. Archivos analíticos de políticas educativas, 22 (41) https://doi.org/10.14507/epaa.v22n41.2014

Stephen J. Ball, S. y Youdell, D. (2008). La privatización encubierta de la educación pública. Londres: Instituto de Educación.

Bobbio, N. (1991). El tiempo de los derechos. Madrid: Sistema.

Bobbio, N. (1985). El futuro de la democracia. Madrid: Plaza \& Janes.

Comité de Derechos Económicos Sociales y Culturales (1999). Observación General $N^{\circ} 13$ http://www.right-to-education.org/sites/right-to-education.org/files/resourceattachments/ONU_Observación_General_13_Derecho_Educación_es.pdf

Comité de los Derechos del Niño / UNICEF (2001). Observaciones generales https://www.unicef.org/ecuador/UNICEF-

ObservacionesGeneralesDelComiteDeLosDerechosDelNino-WEB.pdf

Directrices de Maastricht sobre Violaciones a los Derechos Económicos, Sociales y Culturales, 22 al 26 de enero de 1997.

http://www.derechoshumanos.unlp.edu.ar/assets/files/documentos/directrices-de-maastrichtsobre-violaciones-a-los-derechos-economicos-sociales-y-culturales.pdf

Durkheim, E. (1976). Educación como socialización. Salamanca: Ediciones Sígueme.

Ezcurra, A. M. (coord.) et al. (2019). Derecho a la educación. Expansión y desigualdad: tendencias y políticas en Argentina y América Latina. Saenz Peña: UNTREF.

Ferrajoli, L. (2016). Los derechos y sus garantías. Conversación con Mauro Barberis. Madrid: Trotta.

Finnegan, F. y Pagano, A. (2008). El derecho a la educación en Argentina. Buenos Aires: FLAPE.

Frigerio, G. (2000). ¿Las reformas educativas reforman las escuelas o las escuelas reforman las reformas? Seminario sobre Prospectivas de la Educación en América Latina y el Caribe. Santiago de Chile.

Gargarella, R. y Courtis, C. (2009). El nuevo constitucionalismo latinoamericano: promesas e interrogantes. Santiago de Chile: CEPAL. https://repositorio.cepal.org/bitstream/handle/ 11362/6162/1/S0900774_es.pdf

Kaufman, R. y Nelson, J. (2005). Politicas de Reforma Educativa. Comparación entre países. Santiago de Chile: PREAL.

Lawn, M. (2013). A Systemless System: designing the disarticulation of English State Education. European Educational Research Journal, 12 (2), 447-462 http://dx.doi.org/10.2304/eerj.2013.12.4.447 
Heinrich, C. y Nisar, H. (2013). The Efficacy of Private Sector Providers in Improving Public Educational Outcomes. American Educational Research Journal, 50 (5), 856-894. https://doi.org/10.3102/0002831213486334

Isuani, E. et al. (1991). El Estado Benefactor. Un paradigma en crisis. Buenos Aires: Miño y Dávila/CIEPP.

Julia, D. (1995). La culture scolaire comme objet historique. Paedagogica Historica, 31: sup1, 353 382. https://doi.org/10.1080/00309230.1995.11434853

Lutero, M. (1523). A los magistrados de todas las ciudades alemanas para que construyan y mantengan escuelas cristianas http://escriturayverdad.cl/wpcontent/uploads/ObrasdeMartinLutero/15211525Contine/1523ALOSMAGISTRADOS.pdf

Mas Rocha, S.M., Gorostiaga, J., Tello, C. y Pini, M. (comps.). (2012). La educación secundaria como derecho. Buenos Aires: Stella/La Crujía.

Meix Cereceda, P. (2014). El derecho a la educación en el sistema internacional y europeo. Valencia: Tirant Lo Blanch.

Muñoz, V. (2012). El derecho a la educación: una mirada comparativa. Argentina, Uruguay, Chile y Finlandia. Santiago de Chile: UNESCO.

Olmedo, A., Bailey, P. y Ball, S. (2013). To Infinity and Beyond...: Heterarchical Governance, the Teach For All network in Europe and the making of profits and minds. European Educational Research Journal, $12 \quad$ (4), 492-512. https://doi.org/10.2304/eerj.2013.12.4.492

Paviglianiti, N. (1997). El derecho a la educación: una construcción histórica polémica. Buenos Aires: OPFyL/UBA.

Polanyi, K. (1989). La gran transformación. Crítica del liberalismo económico. Madrid: La Piqueta.

Ruiz, G. (2020). El derecho a la educación: definiciones, normativas y políticas públicas revisadas. Buenos Aires: EUDEBA

Ruiz, G. (2016). El papel de los Organismos Internacionales en la reformas educativas en América Latina. Journal of Supranational Policies of Education, 4, 2-17 https://revistas.uam.es/index.php/jospoe/article/view/5662/6077

Ruiz, G. y Scioscioli, S. (mayo, 2017). El derecho a la educación y la educación secundaria obligatoria en países de América Latina: algunos casos nacionales. Trabajo presentado en el III Encuentro Internacional de Educación Internacional y Comparada: Innovación en educación, instituciones y actores en perspectiva internacional y comparada, Ciudad de México.

Sánchez Viamonte, C. (1907). El pensamiento liberal argentino en el siglo XIX. Tres generaciones históricas. Buenos Aires: Gare. 
Santa Cruz Grao, E. y Olmedo, A. (2012). Neoliberalismo y creación de 'sentido común': crisis educativa y medios de comunicación en Chile. Profesorado. Revista de currículum y formación del profesorado, 16 (3), 145-168. http://www.ugr.es/local/recfpro/rev162ART8.pdf

Tomasevski, K. (2004). El asalto a la educación, Barcelona: Intermon Oxfam.

Tomasevski, K. (2001). Human Rights Obligations: Making Education available, accessible, acceptable and adaptable. Gothenburg: Novum Grafiska AB.

Tröhler, D. (2013). Los lenguajes de la educación. Los legados protestantes en la pedagogización del mundo, las identidades nacionales y las aspiraciones globales. Barcelona: Octaedro.

Verger, A., Fontdevila, C. y Zancajo, A. (2016). The Privatization of Education. A Political Economy of Global Education Reform. New York: Teacher College Press.

Vior, S., Rodríguez, L. y Más Rocha, S. M. (2016). Evaluación, calidad y escuela secundaria en la Ciudad de Buenos Aires (1992-2013). Luján: EdUnLu.

Vincent, G. (dir.) (1994). L'éducation prisonnière de la forme scolaire? Scolarisation et socialisation dans les sociétés industrielles. Lyon: Presses Universitaires de Lyon. https://doi.org/10.4000/books.pul.9522

Volio Jiménez, F. (1979). El derecho del niño a la educación: resumen histórico. En Mialaret, G. (comp.). El derecho a la educación del niño (pp. 19-33). París: UNESCO.

Whitty, G., Power, S. y Halpin, D. (1999). La escuela, el Estado y el mercado. Delegación de poderes y elección en educación. Madrid: Editorial Morata.

Young, M. (2008). Bringing Knowledge Back In. London: Routledge. https://doi.org/10.4324/9780203073667 